\title{
LA-UR-16-23375
}

Approved for public release; distribution is unlimited.

Title: $\quad$ Drinking Water Consequences Tools: A Literature Review

Author(s): $\quad$ Pasqualini, Donatella

Intended for: $\quad$ Report

Issued: 
Disclaimer:

Los Alamos National Laboratory, an affirmative action/equal opportunity employer, is operated by the Los Alamos National Security, LLC for the National Nuclear Security Administration of the U.S. Department of Energy under contract DE-AC52-06NA25396. By approving this article, the publisher recognizes that the U.S. Government retains nonexclusive, royalty-free license to publish or reproduce the published form of this contribution, or to allow others to do so, for U.S. Government purposes. Los Alamos National Laboratory requests that the publisher identify this article as work performed under the auspices of the U.S. Department of Energy. Los Alamos National Laboratory strongly supports academic freedom and a researcher's right to publish; as an institution, however, the Laboratory does not endorse the viewpoint of a publication or guarantee its technical correctness. 


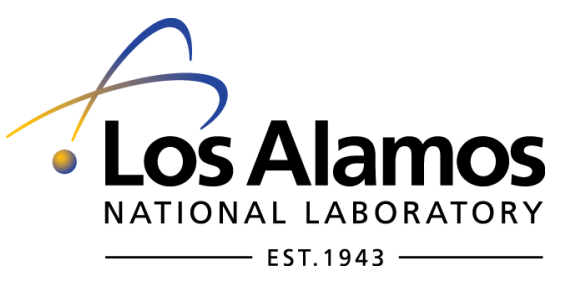

\section{Drinking Water Consequences Tools: A Literature Review}

Dr. Donatella Pasqualini

Los Alamos National Laboratory, A-1: Information Systems And Modeling NM , USA 



\section{TABLE OF CONTENTS}

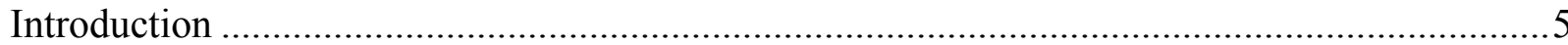

Community-Based Water Resiliency (CBWR) .............................................................. 8

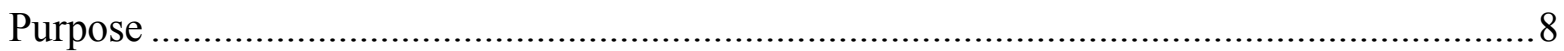

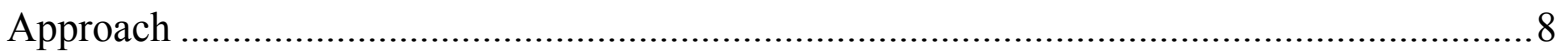

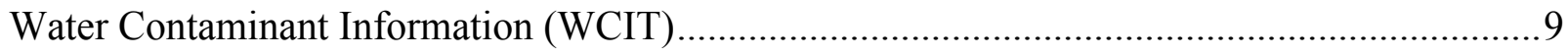

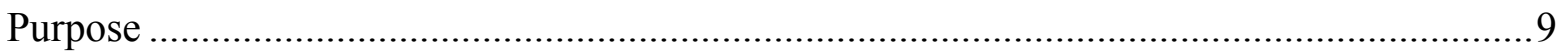

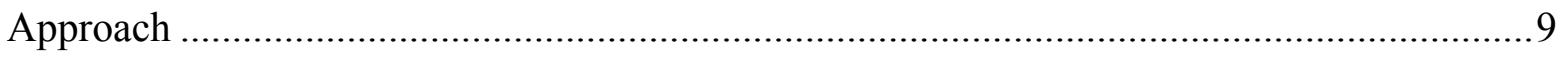

Security and Emergency Management System (SEMS) ............................................... 10

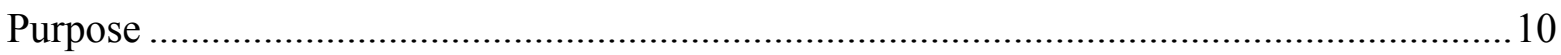

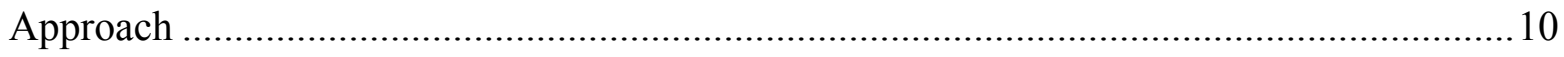

Risk Assessment Methodology for Water Utilities (RAM-W) .......................................... 11

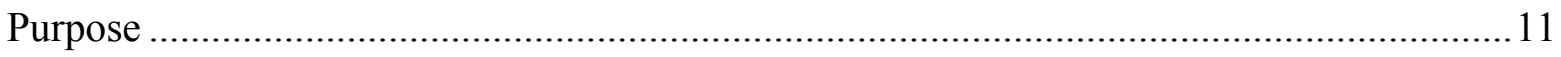

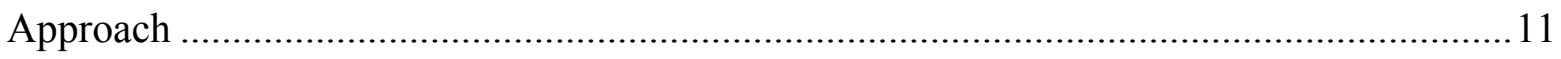

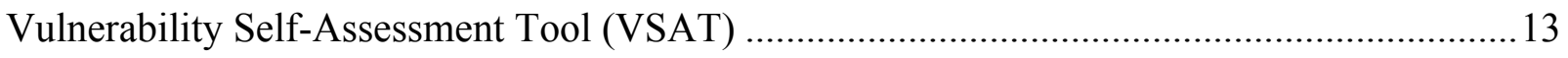

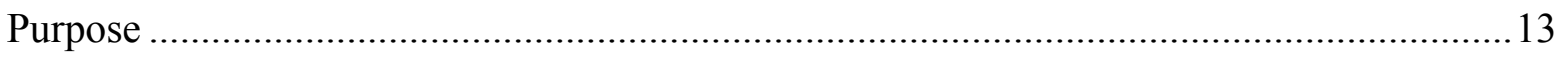

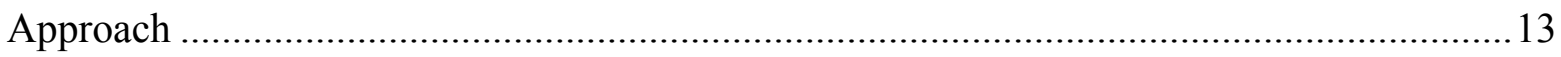

Water Health and Economic Analysis Tool (WHEAT) .................................................... 15

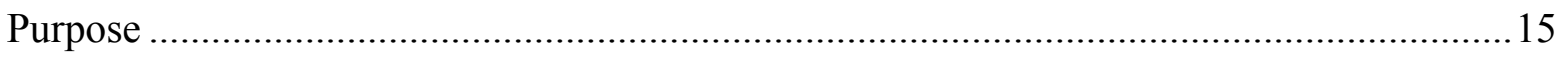

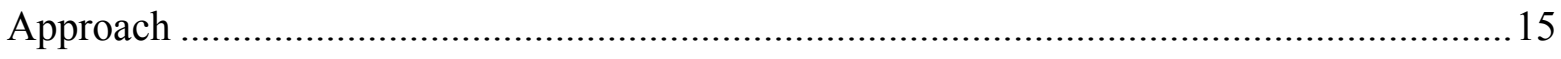

Climate Resilience Evaluation \& Awareness Tool (CREAT) ............................................. 17

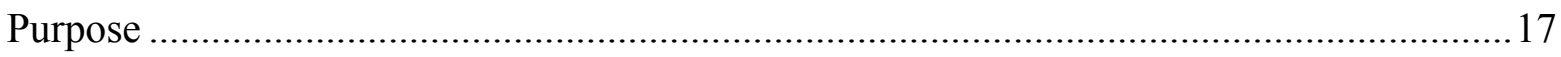

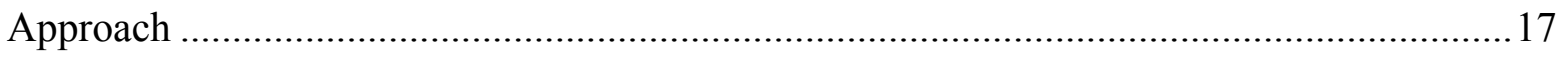

Argonne National Laboratory Resilience Index .......................................................20

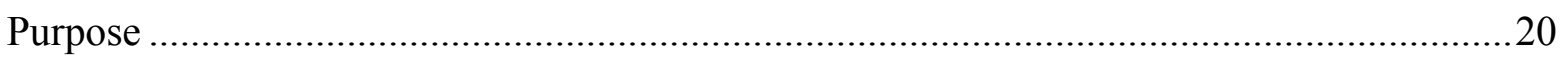

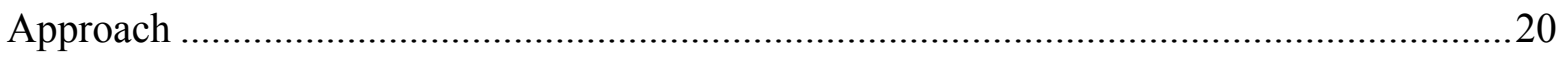

Threat Ensemble Vulnerability Assessment and Sensor Placement Optimization Tool (TEVA-

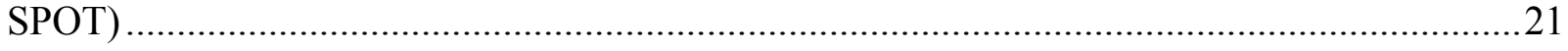

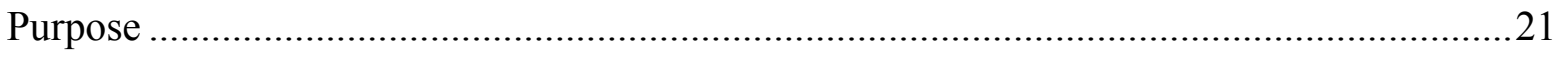

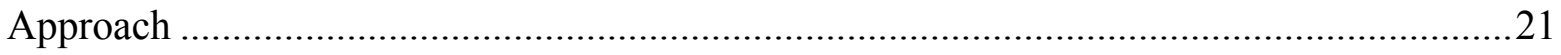

Critical Infrastructure Decision Support Systems (CIP-DSS) ...........................................22

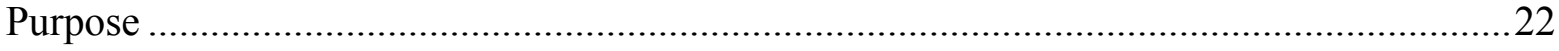

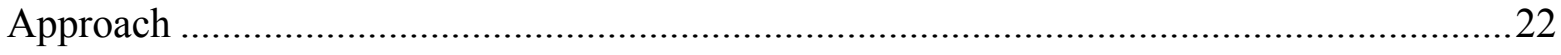

Water System at Master Plan Level (WSMP) Model ...................................................25 


Purpose

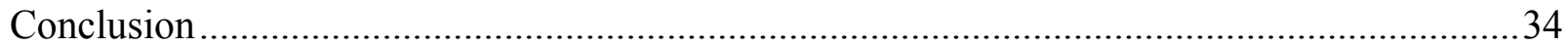




\section{INTRODUCTION}

Water supply and distribution systems are critical to sustaining life and economic activity throughout the world. In the United States, there are more than 53,000 community water systems with nearly a million miles of pipe networks. About $50 \%$ of the United States population is served by only $1 \%$ of the community population systems, indicating that there are many rural water system serving populations over larger geographic areas. There are many threats, natural and human-caused, that could result in service disruption to these systems. For example, much of the water infrastructure in the United States has exceeded or is near exceeding design life expectation. In fact, it is estimated that public water system infrastructure requires funding levels of more than $\$ 380$ billion in the next 20 years to ensure safe public drinking water through 2030 with more than $\$ 230$ billion of that required for medium and smaller water systems (less than 100,000 and 3,300 people, respectively). ${ }^{1}$ Failures in drinking-water infrastructure can result in water disruptions, impediments to emergency response, and damage to other types of critical infrastructure. In extreme situations caused by failing infrastructure or drought, low-water pressure in systems may result in unsanitary conditions, increasing the likelihood of public health issues. The consequences of water system failure also include economic losses - lost revenue, infrastructure repair and replacement costs, direct economic loss to business dependent on water service, and indirect economic losses. To determine water distribution system resilience, it is important to understand the complete social, health, and economic consequences for a range of threats. Moreover, consequence estimation methods must be consistent in order to assess current and future resilience posture.

In support of the goals of Department of Homeland Security's (DHS) National Protection and Programs Directorate and the Federal Emergency Management Agency, the DHS Office of Science and Technology is seeking to develop and/or modify consequence assessment tools to enable drinking water systems owner/operators to estimate the societal and economic consequences of drinking water disruption due to the threats and hazards. This work will expand the breadth of consequence estimation methods and tools using the best-available data describing water distribution infrastructure, owner/assetlevel economic losses, regional-scale economic activity, and health. In addition, this project will deploy the consequence methodology and capability within a Web-based platform.

This report is intended to support DHS effort providing a review literature review of existing assessment tools of water and wastewater systems consequences to disruptions. The review includes tools that assess water systems resilience, vulnerability, and risk. This will help to understand gaps and limitations of these tools in order to plan for the development of the next-generation consequences tool for water and waste water systems disruption.

\footnotetext{
${ }^{1}$ U.S. EPA (2013). "Drinking water infrastructure needs survey and assessment- Fifth report to Congress." United States Environmental Protection Agency, EPA 816-R-13-006. http://water.epa.gov/grants_funding/dwsrf/upload/epa816r13006.pdf
} 
This review examined the following 13 tools:

- Community-based Water Resiliency (CBWR)

- Water Contaminant Information (WCIT)

- Security and Emergency Management System (SEMS)

- Risk Assessment Methodology for Water Utilities (RAM-W)

- Vulnerability Self-assessment Tool (VSAT)

- Water Health and Economic Analysis Tool (WHEAT)

- Climate Resilience Evaluation \& Awareness Tool (CREAT)

- Argonne National Laboratory Resilience Index (ANL-RI)

- Threat Ensemble Vulnerability Assessment and Sensor Placement Optimization Tool (TEVA-SPOT)

- Critical Infrastructure Decision Support Systems (CIP-DSS)

- Water System at Master Plan Level (WSMP)

- EPANET

- $\quad$ EPANET Pressure-Dependent Demand (EPANET-PDD)

Table 1 summarizes the main differences across the considered tools. The following sections provide detailed description of the considered tools, including purpose and approach. 
Table 1. Tools comparison

\begin{tabular}{|c|c|c|c|c|}
\hline Tool & Developer & $\begin{array}{l}\text { Method/ } \\
\text { Approach }\end{array}$ & $\begin{array}{l}\text { Economic } \\
\text { Assessment }\end{array}$ & $\begin{array}{l}\text { AWWA- } \\
\text { J100 } \\
\text { compliance }\end{array}$ \\
\hline $\begin{array}{l}\text { Security and Emergency } \\
\text { Management System (SEMS) }\end{array}$ & $\begin{array}{l}\text { SEMS } \\
\text { Technologies }\end{array}$ & $\begin{array}{l}\text { Qualitative } \\
\text { assessment }\end{array}$ & No & Yes \\
\hline $\begin{array}{l}\text { Climate Resilience Evaluation } \\
\& \text { Awareness Tool (CREAT) }\end{array}$ & $\mathrm{EPA}^{*}$ & $\begin{array}{l}\text { Qualitative } \\
\text { assessment }\end{array}$ & Yes & No \\
\hline $\begin{array}{l}\text { Water Health and Economic } \\
\text { Analysis Tool (WHEAT) }\end{array}$ & EPA & $\begin{array}{l}\text { Qualitative } \\
\text { assessment }\end{array}$ & Yes & No \\
\hline $\begin{array}{l}\text { Vulnerability Self-Assessment } \\
\text { Tool (VSAT) }\end{array}$ & EPA & $\begin{array}{l}\text { Qualitative } \\
\text { assessment }\end{array}$ & Yes & Yes \\
\hline $\begin{array}{l}\text { Risk Assessment Methodology } \\
\text { for Water Utilities (ARAM-W) }\end{array}$ & $\mathrm{SNL}^{* *}$ & $\begin{array}{l}\text { Qualitative } \\
\text { assessment }\end{array}$ & No & Yes \\
\hline $\begin{array}{l}\text { Threat Ensemble Vulnerability } \\
\text { Assessment and Sensor } \\
\text { Placement Optimization Tool } \\
\text { (TEVA-SPOT) }\end{array}$ & EPA & System Modeling & No & No \\
\hline $\begin{array}{l}\text { Hydraulic and water quality } \\
\text { modeling software for pipe } \\
\text { networks (EPANET) }\end{array}$ & EPA & $\begin{array}{l}\text { System Modeling } \\
\text { Detailed network }\end{array}$ & No & No \\
\hline $\begin{array}{l}\text { Community-Based Water } \\
\text { Resiliency (CBWR) }\end{array}$ & EPA & $\begin{array}{l}\text { Qualitative } \\
\text { assessment }\end{array}$ & No & No \\
\hline $\begin{array}{l}\text { Critical Infrastructure Decision } \\
\text { Support Systems (CIP-DSS) }\end{array}$ & LANL ** $^{* *}$ & $\begin{array}{l}\text { System Modeling } \\
\text { System level }\end{array}$ & Yes & No \\
\hline EPANET-PDD & LANL & $\begin{array}{l}\text { System Modeling } \\
\text { Detailed network }\end{array}$ & Yes & No \\
\hline $\begin{array}{l}\text { Water System at Master Plan } \\
\text { Level (WSMP) }\end{array}$ & LANL & $\begin{array}{l}\text { System Modeling } \\
\text { Network system } \\
\text { level }\end{array}$ & No & No \\
\hline
\end{tabular}




\section{COMMUNITY-BASED WATER RESILIENCY (CBWR)}

\section{PURPOSE}

The CBWR tool was developed as part of a larger initiative to enhance the overall community preparedness by increasing awareness of water systems interdependencies with the emergency sectors. CBWR comprises three sections: (1) a qualitative utility selfassessment, (2) a CBWR toolbox, and (3) a water resilience action plan (WRAP) kit. The CBWR self-assessment consists in a list of questions for the stakeholders in order to guide them in identifying critical components in their systems and assessing their systems resilience. A set of suggestions and recommended resources to improve system resilience complement the self-assessment process (CBWR toolbox). CBWR provides more than 400 specific resources to help plan for and respond to drinking water emergencies. CBWR tool includes a process for planning and hosting a community meeting or workshop on water emergencies (WRAP).

\section{APPROACH}

The CBWR tool provides an easy self-assessment step-by-step process that leads users with questions specific to their drinking water system. The questions focus on evaluating the resilience of a water utility in terms of security enhancements, vulnerability assessments, plans for emergency response, contaminant detection, participation in local emergency response planning, and long-term climate change planning. Examples of questions are number of people who live in the community and number of people served by the utility, and on-site drinking water storage capacity. Stakeholders are also asked to list other critical infrastructures or large users served, whose operation depends on the utility service (e.g., hospital, and emergency services). The tool summarizes the user inputs in a Word document report that incorporates generic recommendations to enhance the users community resiliency.

The electronic CBWR tool is available for download free of charge at Environmental Protection Agency (EPA) http://water.epa.gov/infrastructure/watersecurity/techtools/cbwr.cfm. 


\section{WATER CONTAMINANT INFORMATION (WCIT)}

\section{PURPOSE}

Developed by EPA, the Water Contaminant Information Tool (WCIT) is a planning tool for drinking and wastewater contamination incidents and threats. WCIT also provides support in making appropriate response decisions after a contamination event. Although the tool does not estimate consequences, WCIT provides information useful for quantifying the likelihood of water system contamination and the consequent damage, which can supporting vulnerability assessments. WCIT consists in a database of information of over 700 contaminants that could present a significant threat to public health if introduced into drinking and wastewater systems. In addition to the contaminants typically found in drinking water, the WCIT database includes some unregulated but potentially harmful contaminants.

\section{APPROACH}

Information about contaminants includes information on how easy it is to obtain the contaminant by purchasing, harvesting, or synthesizing (availability), level at which the contaminant pose a public health threat if introduced into a water system (toxicity), and how long the agent will remain toxic or infective in water (stability). In addition, WCIT makes available risk calculations that estimate the specific contaminant quantity or the quantity of a particular substance necessary to contaminate a given volume of water.

Summarizing WCIT information is the following:

- Name, Chemical Abstracts Service (CAS) Registry Number

- Physical or pathogen properties

- Availability

- Fate and transport

- Medical and toxicity information

- Early warning indicators

- Field detection and analysis information

- Drinking water and wastewater treatment

- Environmental impacts

- Infrastructure decontamination

The data collected in WCIT are considered sensitive and the access to the WCIT database is restricted to individuals in the water sector. Information about WCIT is found at www.epa.gov/wcit. 


\section{SECURITY AND EMERGENCY MANAGEMENT SYSTEM (SEMS)}

\section{PURPOSE}

Within the scope of helping small utilities to secure their drinking water, the National Rural Water Association (NRWA) developed the Security and Emergency Management System (SEMS) tool. SEMS is a software program for small water and wastewater utilities to self-assess their system vulnerability and resilience.

\section{APPROACH}

SEMS assists utilities in first completing a vulnerability self-assessment through a stepby-step process based on the Association of State Drinking Water

Administrators/NRWA's security vulnerability self-assessment guide for small drinking water systems (population served between 3,300 and 10,000 people). The first step includes providing population and connection count; and defining the utility mission (e.g., provide safe and affordable water for potable use), which may be selected from a pre-loaded list or by supplying a customized mission. To identify the weakness in water system security, users are required to define the system-critical assets and their type using a list provided within the tool. To each asset users need to associate a level of security using a rank that range from low to high. In addition to water and wastewater system critical assets, SEMS allows users to designate critical customers and input customers information.

The second part of the SEMS analysis corresponds to a risk analysis, which coincides with the users pairing each asset with one or more threat, defining existing countermeasures related to each asset/threat pair, and finally associating consequences to each asset/threat pair in terms of number of estimated fatalities and injuries, and amount of financial loss to the community and owner of the water system. In this process SEMS aids the user providing predefined average values for the consequences, in addition to a slit of potential threats. The risk assessment results in a comparison of the consequence and vulnerability of all the selected assets, plotting consequences versus vulnerability. The information selected by the user and the risk assessment results are summarized in a report, which the user may directly submit electronically to the Department of Homeland Security.

The software can be purchased as a CD-ROM from NRWA. Information about SEMS tool is found at http://semstechnologies.com/RAMCAP.asp 


\section{RISK ASSESSMENT METHODOLOGY FOR WATER UTILITIES (RAM-W)}

\section{PURPOSE}

The Risk Assessment Methodology for Water Utilities (RAM-W) was developed by Sandia National Laboratories with the support of EPA and the input from the American Water Works Association Research Foundation. ${ }^{2}$ The RAM-W goal is to evaluate system vulnerability based on the system risk evaluation. The tool focuses on natural disaster and malevolent acts. The RAM-W methodology is based on the methodology originally developed for the security assessment of assets, such as nuclear weapons infrastructures and federal dams. RAM-W is focused on water and wastewater systems. The methodology individualizes the most critical components in the system and compares system components in terms of vulnerability to calculate the highest risk components.

RAM-W was modified in 2007 to comply with the Risk Analysis and Management for Critical Asset Protection (RAMPCAP) creating the RC RAM-W tool. In this new version of RAM-W, RAMPCAP specific assets, threats, vulnerability, and risk table are added to the lists included in RAM-W. The tool has been also recently integrated into the Program Analysis of Risk and Resilience Evaluation (PARRE) framework. ${ }^{3}$ PARRE integrates a suite of resilience assessment tools providing a user interface to present the results and develop management plans to enhance system resilience.

\section{APPROACH}

In the RAM-W process, users respond to a list of questions, with the goal of identify critical water system operations, critical assets and threats, and existing mitigation measures.

The first step of RAM-W methodology is to determine the water system missions and objectives by identifying the services provided by the utility and assigning the highest priority and the most critical customers. The second step determines the most important components in the system (e.g., processes, and infrastructures assets) required to achieve system mission, which, in turn, identifies the most critical components, i.e., single points of failure. Single points of failure include such as critical reservoirs and/or pumps and other sectors critical assets, whose disruption may lead to a failure in the water systems (e.g., electrical substations). The user works through a list of questions to individualize potential threats to the specific critical assets. Potential threats include the disruption of critical infrastructure components of the water system (e.g., reservoirs, pumps and water mains) or of other sectors (e.g., electricity) and system contamination. In the third step, the user assesses the probability of each specific threat based on answers to a list of questions to individualize the threat sources.

\footnotetext{
2 http://www.awwa.org

${ }^{3} \mathrm{http}: / /$ www.parre-pro.com/pages/features
} 
To evaluate the vulnerability of the water system, the user evaluates existing security measures and operational actions to protect against the threats identified in the previous step. These mitigation measures include monitoring water quality and security policies. The user also estimates the level of damage (consequences) for each threat taking into account existing mitigation actions. Once the users identify the system mission, critical components, possible threats, and existing countermeasures, the likelihood of the threats, and the level of consequences, RAM-W summarizes the results prioritizing assets and threats calculating their risk level. The RAM-W approach is based on the following risk equation:

$$
\mathrm{R}=\mathrm{P}_{\mathrm{a}} *\left(1-\mathrm{P}_{\mathrm{e}}\right) * \mathrm{C}
$$

Where $\mathrm{R}$ is the risk, $\mathrm{Pa}$ is the probability that the threat occurs, $\mathrm{Pe}$ is the countermeasure effectiveness, and $\mathrm{C}$ is the consequence due to the threat occurrence. Users can apply the risk analysis results to evaluate whether the risk is acceptable or if new countermeasures need to be implemented to reduce the risk. If the risk results are too high, RAM-W allows the user to evaluate the impacts of upgrades and mitigation strategies on the existing risk adding to the analysis process new countermeasures to reduce the risk.

Utilities need to contact AWWA's customer service at custsve@awwa.org to download the tool, which is available under need-to-know restrictions. Users must sign a nondisclosure agreement. Information about RAM-W tool is found at http://www.parrepro.com/pages/features. A brief description of the tool can be also found in "Evolution of Sandia's Risk Assessment Methodology for Water and Wastewater Utilities (RAM-W)" C.D. Jaeger, M. M. Hightower, and T. Torres in Word Environmental and Water Resources Congress 2010: Challenges of Change pp. 3804-3810 (2010). 


\section{VULNERABILITY SELF-ASSESSMENT TOOL (VSAT)}

\section{PURPOSE}

The Vulnerability Self-Assessment Tool (VSAT) is an EPA computer software tool designed to help drinking and wastewater utilities assess their vulnerabilities to natural and manmade hazards. Originally developed for wastewater systems, mainly by the Association of Metropolitan Sewerage Agencies with the support from EPA, VSAT was later modified for drinking water. VSAT assesses the potential risk to a water and wastewater facilities in terms of public health and economic consequences. Through a step-by-step assessment process the tool guides utilities in quantifying consequences in terms of monetized risk and resilience of additional measures to reduce risks. Using VSAT users may compare different mitigation measures through a costs-risk evaluation that assesses reductions in risk against implementation costs of new mitigation countermeasures. In addition, VSAT includes a module to help the utilities in developing and/or updating their emergency response plans.

VSAT has been modified to be consistent with the ANSI/AWWA J100-10 $0^{4}$ Standard for risk analysis and management for critical asset protection. Results from SEMS assessments and from the EPA WHEAT consequence assessment tool can be incorporated directly into VSAT to estimate risk and resilience.

\section{APPROACH}

The step-by-step VSAT process includes four steps. The first step consists in the characterization and identification of assets potentially at risk. VSAT includes a list of assets from where the user may choose. The assets in this list are grouped into four categories: physical, knowledge base, information technology, and customers, and employees. Water and wastewater systems infrastructure and facilities including surface water and ground water sources represent the physical assets. Utility information and data associated such as permits, certificates to the utility employ records fall under the knowledge base assets. Information technology category represents assists to the utility management information system to SCADA systems. Customers and employees list represents respectively customers' type and individuals employed distributions categorized by physical location. Users also need to prioritize the assets based on what the user thinks is the level of consequences (criticality), using a scale from 1 to 10 with 10 the highest consequence. In addition, to ascertain system vulnerability, VSAT requires the user to identify one or more natural or manmade events that may threaten a specific asset.

The second step consists in identifying specific existing countermeasures used to mitigate the identified vulnerability. For example, the information-system hacking threat firewalls and network monitoring can be employed to reduce the level of vulnerability.

\footnotetext{
${ }^{4}$ AWWA J100-10 (R13) Risk and Resilience Management of Water and Wastewater Systems (RAMCAP), American Water Works Association, 2010
} 
Once the asset/pair list and existing countermeasures are defined, the user is required to associate public health and economic consequences to each asset/threat pair (third step). Specifically, the user needs to provide an estimate for number of fatalities and injuries expected to occur in case the asset is affected by a threat. In addition, the user inputs the number of days of services lost and financial impacts. For each asset/threat pair, the user also needs to estimate the probability that the selected threat will occur to the selected asset and likelihood of the damage based on the system capability to reduce the damage. In case of natural threats, such as tornadoes and earthquakes, VSAT provides probability of occurrence based on historical events.

The main result of the VSAT analysis is a consequence and resilience evaluation that accounts for the countermeasures already existing in the system, i.e., a baseline assessment (fourth step). At first the user is required to enter basic utility information: (1) utility location, (2) financial information in detailed utility data, (3) water utility properties, such as average daily water service and average rate of wastewater; (4) consequence determination, such as the value of statistical life and value of a statistical injury. If the user is unable to define specific values for the utility, VSAT includes a U.S. average value for each of the above parameters. Based on the inputs entered by the user, the tool estimates three resilience metrics: (1) Asset resilience metric, calculated as the product of the amount of water lost per day times the likelihood of damage and times the likelihood of damage; (2) owner's economic resilience metric, estimated as the product of the assets resilience metric and the water or the wastewater service cost; and (3) community resilience metric, which captures the monetized risk for the community, which is defined as the product of the regional economic impact, the likelihood of damage, and threat occurrence. In addition to the baseline, VSAT allows an improvement assessment, which estimates the impacts of new countermeasures in terms of costs-risk benefit analysis. Choosing from a preloaded list, the user may identify new mitigation actions. The user is required to associate a reduction risk level for each action and enter implementation, operating, and management costs. Using these inputs, VSAT recalculates the reliance metrics as in the Baseline assessment.

Using the baseline and improvement assessment process, utilities can assess consequences, vulnerability, and risk associated with potential threats and compare how vulnerability and risk is reduced by implementing new countermeasures. The results are summarized in a Word document and an Excel file.

VSAT is available for download free of charge at http://yosemite.epa.gov/ow/SReg.nsf/description/VSAT. VSAT software includes a technical report and a user guide. 


\section{WATER HEALTH AND ECONOMIC ANALYSIS TOOL (WHEAT)}

\section{PURPOSE}

EPA developed the Water Health and Economic analysis Tool (WHEAT) to support water and wastewater utility assessment of the impacts of adverse events in the water sector. WHEAT supports impacts analyses for three specific events: (1) the failure of one or more assets; (2) the release of a stored hazardous gas, and (3) intentional contamination of a potable water distribution system. Based on user input, WHEAT assesses consequences in terms of public health and utility-level consequences and regional economic. The tool provides order of magnitude estimates of injuries, illnesses, and fatalities in case of system contamination and in case of system assets loss lost revenues, changes in operating costs, assets repair costs, and direct and indirect regional economic consequences.

WHEAT summarizes baseline, scenarios and consequences estimates in a report that the user may save into a Word document and an Excel file. The reported consequences analysis may support utilities during risk management planning providing with more detailed consequences assessment when site-specific modeling is not available.

\section{APPROACH}

The WHEAT consequence analysis process has (1) a user inputs phase and (2) an analysis and tool outputs phase. WHEAT gathers the inputs necessary to develop the analysis providing the user with a list of questions. During this step the user defines the analysis scenario; provides inputs to characterize the water system, including utility location, population served, water production value, lengths of distributions lines, utility financial information, interest rate on capital expenditures, average annual household water cost, and residential flow. The user also enters inputs to characterize the scenario and its likely effects on potable and wastewater services.

Users can select default values for most of these inputs or add their own values. Default values imbedded in WHEAT include drinking water utility connections for residential, non-residential, and wholesale in unit of person (i.e., number of connections served by the system), water production in millions of gallon per day, length in miles of distribution system, and utility revenues and expenses.

In defining the scenario, users are required to identify the affected assets, the damage level of each asset, the associated repair and replacement costs of each asset, and service loss profile. WHEAT generates a list of assets and provides pre-specified values for the costs and loss profiles in case the user is not able to quantify those values.

Once the inputs are collected, users can run the consequences analysis. The impacts of a gas dispersion or water distribution contamination are estimated in terms of total number injuries, illnesses, and fatalities in addition to utility level financial consequences.

Simplified physics-based models of gas and contaminants dispersion support the analysis using inputs included in WHEAT in addition to the inputs entered by the users. WHEAT 
simulates the dispersion of the hazardous gas using the utility location (i.e., State) entered by the user to infer weather conditions, such as wind speed and temperature, which are necessary inputs for the dispersion model.

WHEAT also estimated the consequences for loss of asset scenarios in terms of water and wastewater service interruption, lost sales revenues, increased utility operating costs, and asset repair and replacement costs. Most of these consequences are calculated as linear relations of inputs entered by the users. In addition, WHEAT estimates direct, indirect, and induced regional economic impacts in terms of loss of jobs and gross domestic product. WHEAT includes a database of state-level inputs outputs multipliers from the U.S. Bureau of Economic Analysis Regional Input-Output Modeling Systems (RIMS II) to characterize the regional economic structure and estimate the regional economic impacts.

WHEAT consequence analysis summarizes scenarios, inputs, and consequences results in a report that users may employ during a risk assessment of their water and/or wastewater systems.

WHEAT is available for download free of charge at http://water.epa.gov/infrastructure/watersecurity/techtools/wheat.cfm. An overview of the tool is provided at http://water.epa.gov/infrastructure/watersecurity/techtools/upload/epa817f14003.pdf and a technical report and user guide are included in the tool itself. 


\section{CLIMATE RESILIENCE EVALUATION \& AWARENESS TOOL (CREAT)}

\section{PURPOSE}

Unlike other EPA tools, the Climate Resilience Evaluation and Awareness Tool (CREAT) pays particular attention to the consequences that climate change may cause to water systems. Changes in precipitation and runoff patterns; sea-level rise; extreme weather events, such as drought, and storms; temperature changes; and consequent changes in water availability and quality may have critical impacts on water utilities operations. As part of the EPA's Climate Ready Water Utilities (CRWU) initiative, EPA developed CREAT to aid drinking water and wastewater utility owners/operators in understanding potential climate change threats and in assessing their related risks. By providing users with historical and projected measures of climate change indicators, CREAT guides utilities through an evaluation of how potential threats may impact facilities operation and missions. In addition, using both risk assessment and scenariobased decision-making approaches, CREAT allows users to examine mitigation options to address potential threats. The assessment results include a list of assets at risk, potential threats to those assets, the likelihood of occurrence of each threat, and the overall level of consequences for each asset/threat pair. If the assessment analysis includes the development of new mitigation actions, the results include costs and risk reductions related to the mitigation options. These results are automatically summarized in a report and saved as a Microsoft Word file.

As part of the CRWU initiative, CREAT has been employed in assessing climate-related risk for about 20 drinking water and wastewater utilities.

\section{APPROACH}

The approach used by CREAT is similar to the one used in other EPA's tools, such as VSAT and WHEAP. CREAT mainly differs in the type of threats, scenarios, and adoption options provided, which are mostly climate change-related. In addition, CREAT makes climate data and information available to assist users in evaluating threats, quantifying their likelihood of occurrence, and estimating the consequence level of the threats to specific assets.

The first step of the assessment the user selects the climate-related events that could potentially threaten their water system. Users select from a list of potential climaterelated threats. The list is based on the assessment of several well-known climate information sources. The user may also examine more detailed climate information, such as projected values or changes of temperature and precipitation, 24-hour event precipitation, and level of sea rise. Temperature and precipitation projections consist in downscaled outputs of different Global Circulation Models ${ }^{5}$ and they are provided for three different climate scenarios (hot/dry, central, and warm/wet). CREAT provides sea-

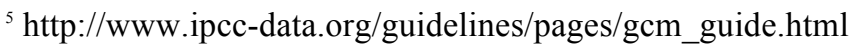


level rise projections for three different effects from ice melt, while the 24-hour precipitation events projections are based on the NOAA analysis .

The second step requires the user to define the likelihood that the specific threat may occur for each selected threat. The likelihood may be specified using a value from low to very high probability of occurrence. The user can use the available climate-related data and information to assign the likelihood to each threat.

Once the threat inventory is populated, the user develops an asset inventory (third step). The tool provides a list of standard assets organized by utility types (drinking water, wastewater, or combined) and grouped in two categories: infrastructure assets, which are critical for utility operations, and natural resources assets, which are essential for maintenance and protection (e.g., surface water, wetlands, flood plains). When both inventories are completed, the fourth step before starting the risk assessment requires pairing each asset with one or more threats.

When assets and associated threats are characterized, the tool guides the user through a risk assessment process, which accounts for existing mitigation measures (baseline risk assessment) or includes new adaptive options that may enhance the system resilience.

The Baseline risk assessment evaluates the consequences associated to each threat/asset pair considering the risk reduction measures already in place. The user defines the protective measures already listed in the system. It is left to the user to identify potential consequences for each asset/threat pair and to quantify the severity of the consequences. CREAT provides the user with five consequences categories (utility business impact, utility equipment damage, source/receiving water impacts, environmental impacts, and community public health impacts) and four levels of severity (from low to very high) for each category. For each threat/asset pair, the user needs to associate a severity level to each consequence group, considering the existing protective actions.

The baseline risk assessment displays the threat likelihood of occurrence selected by the user and calculates the overall level of consequences for each asset/threat pair. The overall level of consequences for a specific asset/threat pair corresponds to the highest level of severity in all the five consequences groups, converted the severity level in a number from 1 to 4 ( 1 to low severity, and 4 to high severity). The Baseline assessment does not include costs or economic analysis.

In addition to the baseline, the tool allows a second risk assessment process to determine the ability of the system to enhance its resilience though the implementation of new adaptive measures. As with the baseline, the tool provides the user with a library of climate change-related adaptive actions to reduce the impacts of climate change. Each adaptive option is associated to a risk reduction value and an implementation cost.

The resilience analysis uses the same process employed in the baseline; users estimate the impacts of potential mitigation actions and compare distinct adaptation options. The user may associate an adaptive action for each asset-threat pair. The user is required to associate (1) implementation and operating and management costs and (2) a risk 
reduction level for each selected adaptive measure. CREAT provides a list of pre-defined adaptive measures and relative costs. The list groups the adaptive options into categories (expanded operating flexibility, expanded capacity, and alternative strategies). The list is specific to the region and the type of facility considered. Costs are a requirement for a cost/benefit analysis, which is the core of the resilience assessment. In this analysis, the benefit corresponds to the change in risk from reducing consequences from each threat due to the implementation of adaptive measures. It is quantified by the risk reduction units. The tool calculates total annual costs associated with new measures as the sum of all the costs and also estimates the ratio between the risk reduction units and the total costs as metrics to aid the user in comparing different measures during a decision-making process.

The baseline and the resilience analysis results are summarized as the overall level of consequences and, in the case of implementation of new adaptive actions, the results report the costs and risk reductions related to the mitigation options. CREAT summarizes the results and all the inputs the users enter in a report and saved as a Microsoft Word file

One fundamental difference between CREAT and other EPA's consequence tools is the time dimension. In VSAT and WHEAT, the threat-asset pairs and the threats likelihood do not change over time and the only requested time-related information is the disruption duration, which is used to calculate revenue loss or capital costs, in case of asset reconstruction. In CREAT, threats, likelihood of threats, and adaptive options are provided at multiple future time horizons. The two time periods capture the periods that have climate projections are available—2020 to 2049 and 2020 to 2074 .

CREAT version 2.0, updated in 2011, is available for download free of charge at http://water.epa.gov/infrastructure/watersecurity/climate/creat.cfm, where general information about the tool can be found as well. A detailed tool methodology and data sources description is included in the tool. 


\section{ARGONNE NATIONAL LABORATORY RESILIENCE INDEX}

\section{PURPOSE}

In collaboration with the DHS Protective Security Coordination Division, Argonne National Laboratory developed the Resilience Index (ANL-RI) that consists in a methodology to estimate the resilience of potable and wastewater systems along with other critical infrastructures. ${ }^{6}$ Unlike VSAT, WHEAT, and RAM-W self-assessment tools, RI is intended to be estimated by the Department of Homeland Security. RI enables the comparison of water systems to prioritize funding and assistance.

\section{APPROACH}

The ANL-RI is the result of a large number of variables combined in a single index. RI estimates robustness, resourcefulness, and recovery. Its value ranges from 0 (low resilience) to 100 (high resilience) and it compares the level of critical infrastructure resilience in order to guide prioritization of limited resources for improving resilience. The RI calculation is based on the collection of a large number of variables ranging from physical security, security management, security force, information sharing, protective measures assessment, and dependencies. RI estimates (1) robustness, which is based on parameters that measure redundancy, prevention, and maintaining key functions; (2) resourcefulness, which includes parameters that estimate training, awareness, protective measures, stockpiles, response, new resources, and alternative sites; (3) and recovery, which combines measuring restoration and coordination variables. RI supports an improved understanding of different ways to enhance resilience accounting for (1) increasing physical security measures to prevent an incident, (2) supplementing redundancy to mitigate the effects of an incident, and (3) enhancing emergency action and business continuity planning to increase the effectiveness of recovery procedures.

RI methodology was developed as an interactive user interface to support DHS in analyzing existing response and recovery methods at facilities and to identify potential ways to enhance resilience.

Information about Argonne National Laboratory RI is found at Fisher 2010. ${ }^{11}$

\footnotetext{
${ }^{6}$ R.E. Fisher et al. Constructing a Resilience Index for the Enhanced Critical Infrastructure Recovery Program. Lemont, IL: Argonne National Laboratory. ANL/DIS-10-9 (2010).
} 


\section{THREAT ENSEMBLE VULNERABILITY ASSESSMENT AND SENSOR PLACEMENT OPTIMIZATION TOOL (TEVA-SPOT)}

\section{PURPOSE}

Developed by EPA, TEVA-SPOT provides support for the design, development, and evaluation of water contamination-warning systems, with the goal of enhancing resilience to contamination incidents.

\section{APPROACH}

TEVA-SPOT sensor placement optimization tool can calculate contamination concentrations across a water distribution network. ${ }^{7}$ Based on the location where the contaminant enters the system and the quantity and rate of contaminant introduced, the tool simulates the spatial and temporal impacts on customers. In specific, TEVA-SPOT calculates the number of people exposed to the harmful levels of contaminants and the number of pipes contaminated. In TEVA-SPOT, the risk of contamination in water distribution systems is calculated using the standard risk equation:

$$
\mathrm{R}=\alpha * \mathrm{C}
$$

Where $\alpha$ is the probability that a contamination event occurs and $\mathrm{C}$ is the consequence of the threat (e.g., number of people or pipe exposed). The probability is calculated as the likelihood of a particular contamination event occurring.

TEVA-SPOT is available for download free of charge at http://cfpub.epa.gov/si/si_public_record_report.cfm?dirEntryId $=254745 \&$ fed_org_id $=12$ $53 \&$ subject $=$ Homeland $\% 20$ Security $\% 20$ Research\&; view $=$ desc\&sortBy $=$ pubDateYear\&s howCriteria $=1 \&$ count $=25 \&$ searchall='TEVA $\% 20$ SPOT'.

\footnotetext{
${ }^{7}$ J.Berry, E. Boman, L. Riesen, W.E. Hart, C.A. Phillips, J.P. Watson and U.S. Environmental Protection Agency. TEVA-SPOT Toolkit and user's manual - version 2.5.2 U.S.A Environmental Protection Agency, Washington, DC. EPA/600/R-08/041B, 2012. and R. Murray, T. Haxton, R. Janke, W.E. Hart, J. Berry, C.A. Phillips (2010) Sensor network design for drinking water contamination warning systems: A compendium of research results and case studies using the TEVA-SPOT software. Technical Report Cincinnati, OH: U.S.A Environmental Protection Agency. . EPA/600/R-09/141, 2010
} 


\section{CRITICAL INFRASTRUCTURE DECISION SUPPORT SYSTEMS (CIP-DSS)}

\section{PURPOSE}

Sponsored by the U.S. Department of Homeland Security, the Critical Infrastructure Protection Decision Support System (CIP-DSS) is a computer simulation and decision analytic tool intended to provide insights for making critical infrastructure protection decisions. Simulating the dynamics of critical infrastructures in a generic U.S. metropolitan area, the tool informs decision makers selecting between alternative mitigation measures and operational tactics to protect critical infrastructure against existing and potential future threats. CIP-DSS assists decision makers as they (1) compute public health and safety, economic, public confidence, national security, and environmental impacts; (2) identify choke points in infrastructures (i.e., areas where attacks may have the highest risk areas); (3) determine the highest risk areas through a fully integrated risk assessment process, which explicitly and rigorously accounts for uncertainties in threats; and (4) select the investment strategies that have the most impact in reducing overall risk.

Unlike most other risk assessment tools, CIP-DSS goes beyond the limited calculation of first-order consequences in one or just a few infrastructure systems. CIP-DSS models the primary interdependencies that link critical infrastructure and key resources together and calculates the impacts that cascade into these interdependent infrastructures and the national economy. Potable water and wastewater sectors are included in the critical infrastructures modeled in CIP-DSS. Impacts of disruptions in a water system can be quantified by simulating the water systems separately or accounting for the interdependencies with other infrastructures.

\section{APPROACH}

CIP-DSS comprises consequences models for critical infrastructure and key resources. The consequence models are linked through their strongest interdependencies. The system tracks the propagation of an disturbance in the water sector, for instance, into the energy, emergency services, public heath, and government sectors. The outputs of the consequences models are captured in a database from which consequence metrics are convolved with decision-maker risk profiles and value trade-offs. Multi-attribute utility functions are used to compare alternative infrastructure protection strategies and help build consensus among stakeholders.

CIP-DSS is different from the tools described before which consist in a qualitative assessment. Although at high level CIP-DSS models the systems main components simulating the dynamics of single infrastructure sectors. CIP-DSS also couples separate infrastructure sectors to each other based on their interdependencies. CIP-DSS uses a system dynamics modeling, simulation, and analysis approach to conduct consequences assessments and risk analyses. Dynamic processes are represented in CIP-DSS infrastructure sector simulations by differential equations, discrete events, and codified rules of operation. The CIP-DSS metropolitan model has about 4,500 variables, 
comprising 100 interdependences across sectors.

The water module, which uses 156 variables to simulate system dynamics, simulates the process of a single potable water distribution system (PWDS) that serves a metropolitan population of approximately 2.5 million people. PWDS includes two sub-modules: the main module (treatment process) models the water treatment process, its supply and the clean water daily distribution; the second module (contamination process) models a generic contamination scenario. Figure 1 shows the water model main module. Due to the system dynamics modeling approach employed in CIP-DSS, the detailed water distribution network topology is not explicitly represented. The main module represents (1) raw water sources (e.g., reservoirs, rivers, groundwater), (2) water treatment process, (3) storage of treated water, (4) damage of the PWDS, (5) repair to the PWDS, and (6) distribution of water and end-user demand. The processed water is distributed to different end-users through consumption flows. The end- users are divided (subscripted) into five different classes: residential, commercial, industrial, public health, and other users. There are a number of interdependencies between the potable water infrastructure and other infrastructures. The PWDS model is coupled with other infrastructures, such as metropolitan energy, transportation, and economic.

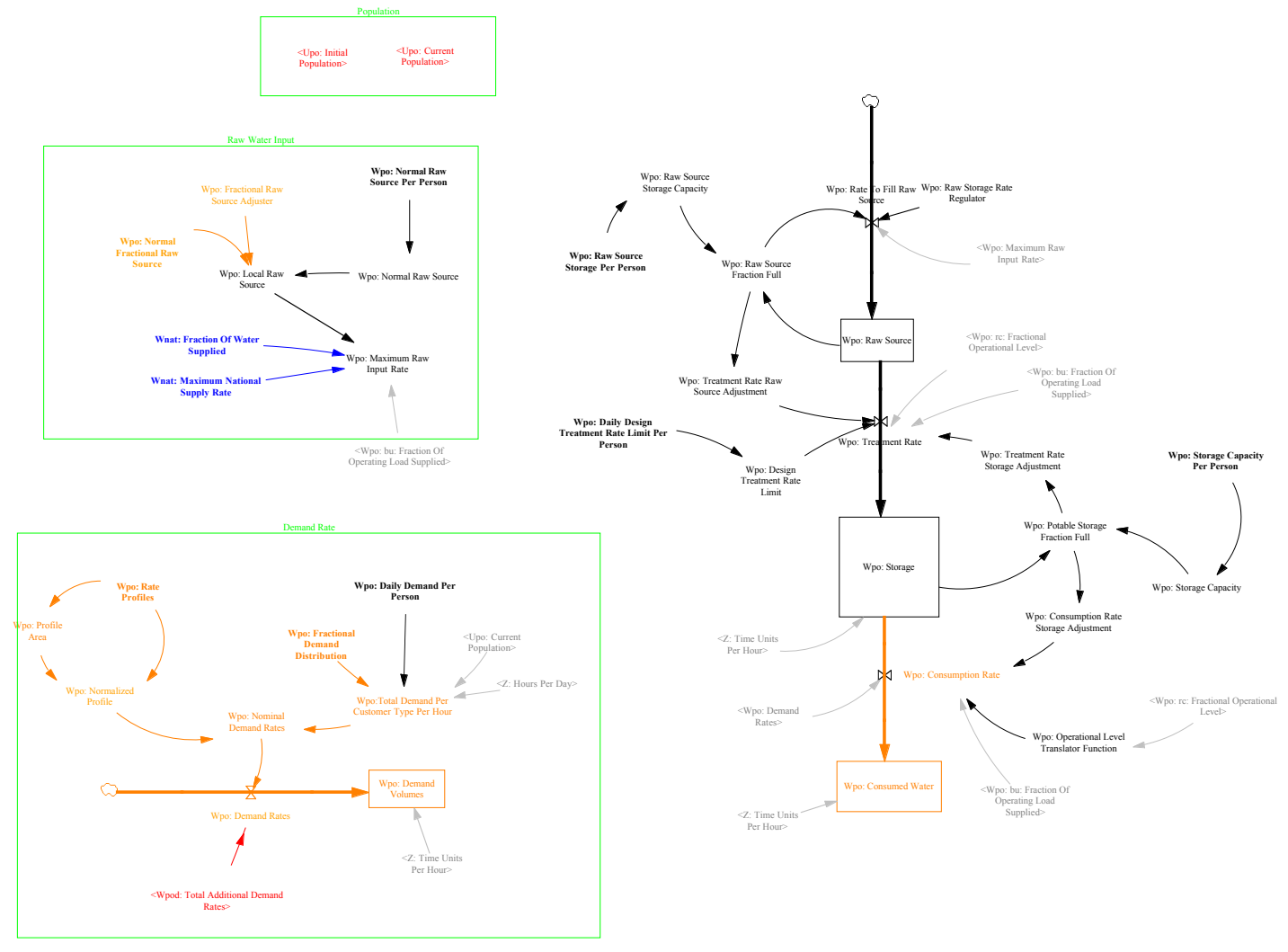

Figure 1 CIP-DSS: Main influence diagram for a metropolitan potable water distribution system

CIP-DSS includes default input values that correspond to average values for an U.S. urban area with a population of 2.5 million people. Inputs parameters may be changed to 
new values specific of the area of interest. Water module inputs parameters include reservoirs and ground water sources capacity, storage tanks volume, and daily water demand value and profile. The decision analysis in CIP-DSS consists of comparing a baseline scenario pair with one or more alternate scenario pair. In the base scenario pair, CIP-DSS calculates the consequences with and without disruption under business as usual conditions and in the absence of additional mitigation measures. In the alternate scenario pair, a specific set of additional optional measures are in place and CIP-DSS estimates the consequences with and without disruption. Comparing the alternate scenario pairs with base scenario pairs indicates the effects that various investments and strategies could have if implemented by decision makers. Each scenario requires a separate simulation over a user-defined period.

CIP-DSS translates simulated fatalities, illnesses, and injuries; economic costs; lost public confidence; and national security impacts into a single measure of merit for each mitigation measure, operational tactic, or policy option considered by a decision maker. Preferred options are plotted against threat or incident likelihood.

CIP-DSS reads input parameters from and writes output time series to an OracleTM relational database of consequence metrics, which are abstracted into a much smaller set of "decision" metrics. The decision support software (written in Visual BasicTM) accesses the decision database to compute utility values for various scenarios and alternatives.

Developed for DHS, CIP-DSS is not available to the public. Information about CIP-DSS tool is found at Bush 2005 and 2004. ${ }^{8}$

${ }^{8}$ B. ${ }^{\text {Bush, L. Dauelsberg }}$, S. DeLand, R. LeClaire, D. Powell, and M. Samsa. Critical Infrastructure Protection Decision Support System (CIP/DSS) Project Overview Report no. LA- UR-05-1870. Los Alamos National Laboratory, 2005. And B. Bush, L. Dauelsberg, M. Ebinger, R. LeClaire, D. Powell, S. Ramsmussen, D. Thompson, C. Wilson, M. Witkowski, A. Ford, and D. Newsom. Metropolitan Critical Infrastructure Model. (version 8.1) LA-CC-04-088, Los Alamos National Laboratory, 2004. 


\section{WATER SYSTEM AT MASTER PLAN LEVEL (WSMP) MODEL}

\section{PURPOSE}

The Water System at Master Plan Level (WSMP) model was developed by LANL to simulate the consequences of a disruption in an urban water distribution system. WSMP estimates consequences in terms of geospatial distribution of the unmet water demand and population impacted. WSMP for a specific metropolitan area is a stand-alone application that can simulate different disruption scenarios (e.g., closing a water tan, deactivate a pump station or reduce a reservoir outflow) in real time to quantify the consequences to the system. The tool models scenarios of disruptions to specific water systems. Using system level information of the water distribution system usually available in the city master plan, WSMP can be employed to develop a user interface that the utilities may employ to quantify consequences of water system disruption and individualize critical assets within the system. Figure 2 depicts the master plan sketch of LANL developed this tool as part of its work on National Infrastructure Simulation and Analysis Center (NISAC) program, supported by Department of Homeland Security.

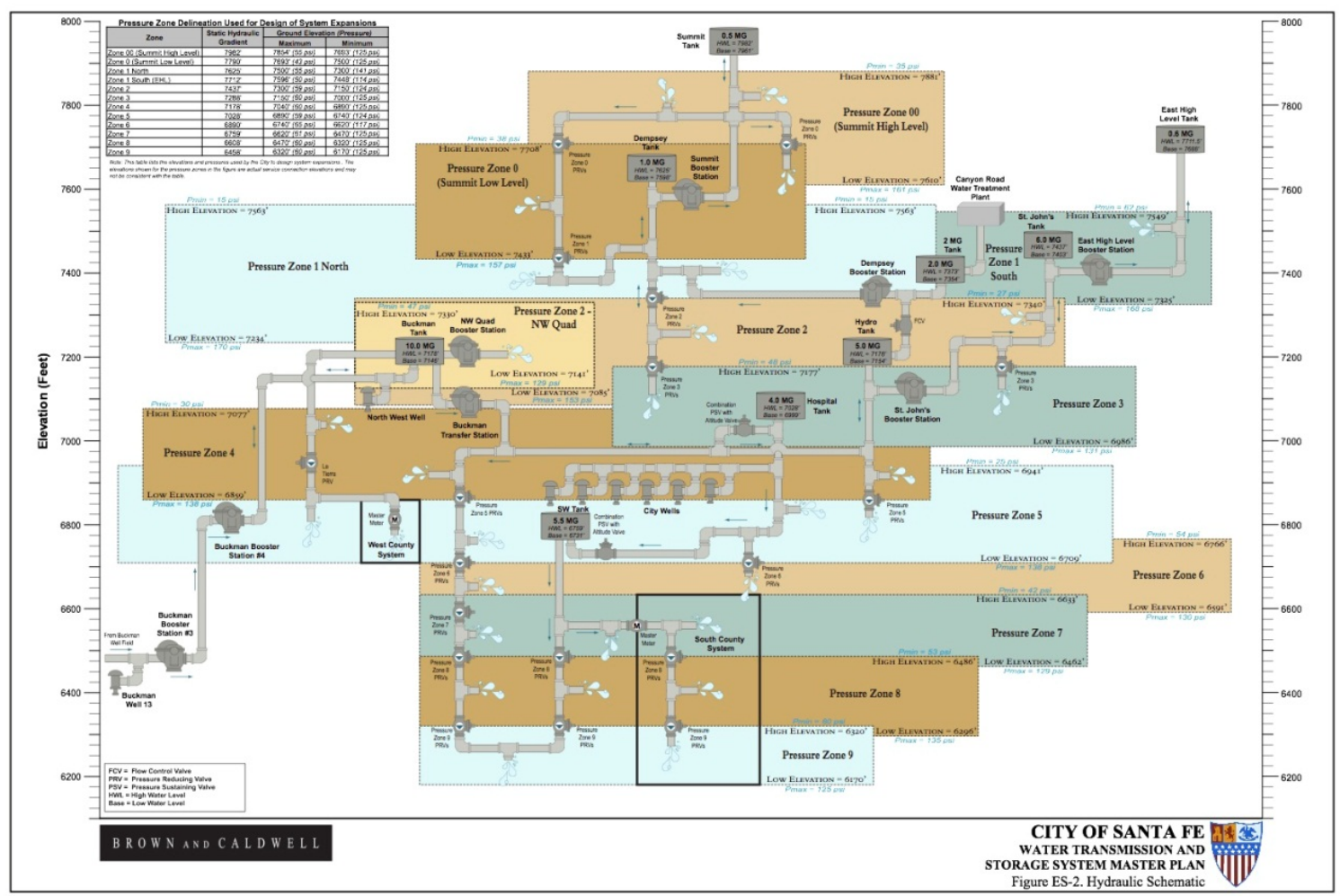

Figure 2. Water system-level schematic from a master plan?

\section{APPROACH}

\footnotetext{
${ }^{9}$ City of Santa Fe Web site, "Transmission \& Storage System Master Plan," www.santafenm.gov/?nid=1865, accessed February 1, 2013.
} 
Like CIP-DSS, WSMP uses a system modeling approach to assess consequences. The WSMP model simulates the water system of a metropolitan area using details provided in a city's water system master plan. A city water system master plan represents a simple schematic of the water system distribution network. It usually includes major reservoirs and groundwater sources; major infrastructure assets, such as tanks, pump stations, and major junctions interconnections among those assets; and, in some cases, the master plan may provide elevations and aggregated water demands associated to specific pressure zones. Usually a sketch of the system network is often provided by a city as a publically available data and part of the annual urban water plan. WSMP models primary requirement is to determine water availability of different pressure zones and estimate shortfalls to junctions due to changes in water supply (e.g., climate change and seasonality) and demand (e.g., water conservation policy) using the limited information provided by the water system master plan.

The WSMP model provides a high-level representation of the water distribution system of a metropolitan area. In this context, high-level means the WSMP model does not model the physics of the system (e.g., solving hydraulic equations to model water flows in specific pipes) and all the system components but rather the water system at the system level modeling only the main system elements. Figure 3 shows the WSMP model of Santa Fe, NM, water distribution system. The hydraulic network topology is specified but within the level of aggregation represented by the master plan. The model tracks the time evolution of the balance between water supply and demand accounting for capacity, supply, demand, product, and information flows. Different elements are connected within the model to construct the master plan system. 


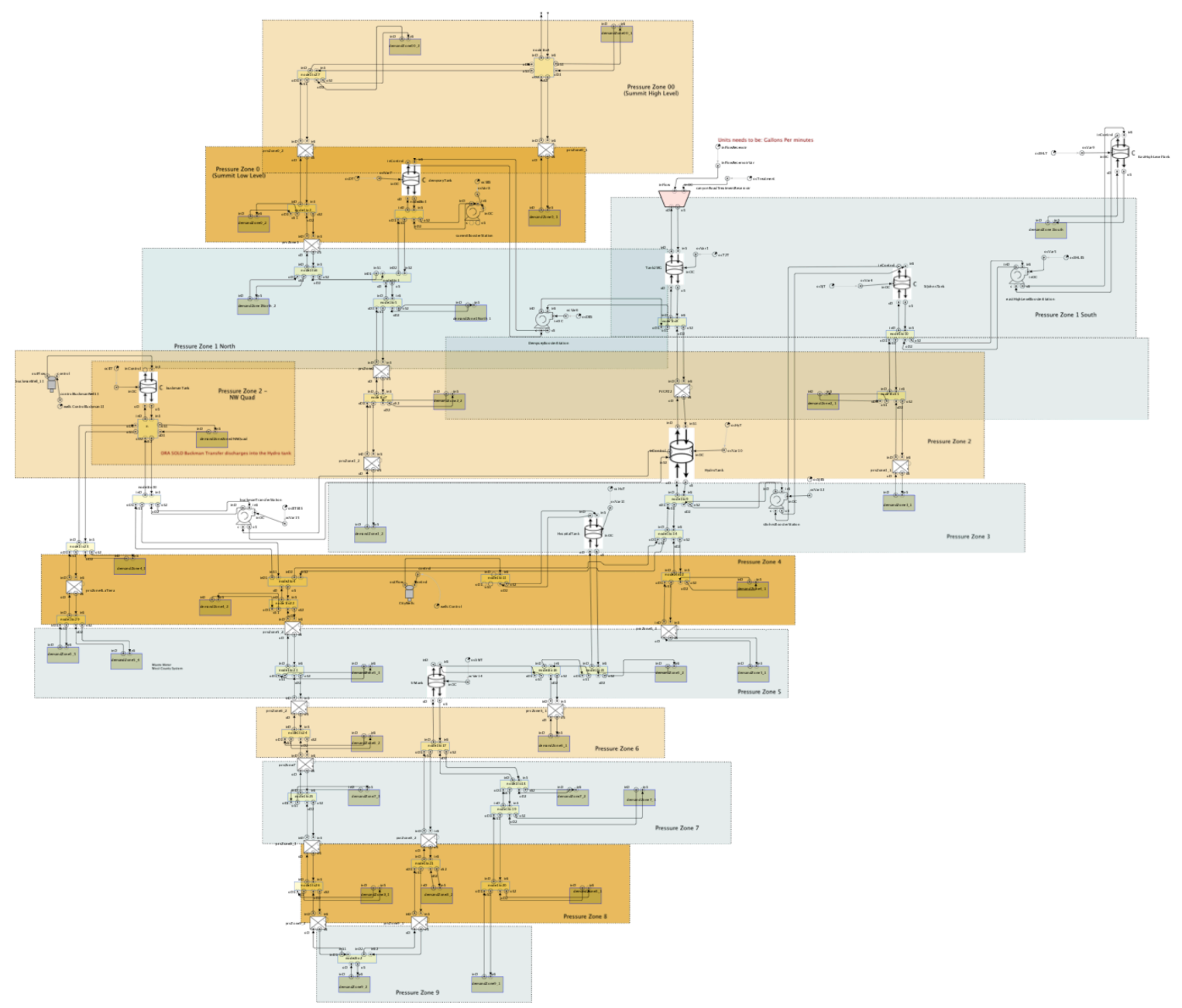

Figure 3 WSMP model for Santa Fe, NM, water distribution system.

There are three categories of elements. The first category consists of the elements required to describe the water supply, such as tank, tank linked to a booster station, reservoir, and ground water wells. These supply elements are characterized by specific input parameters such as maximum capacity, level, elevation, and operational capacity. This category also includes an element named demand. The master plan usually associates a limited number of "outlets" with each pressure zone, aggregating all the junctions existing in the specific pressure zone. The demands in the models are these outlets. The amount of water demand associated to the outlet and its elevation or its pressure zone define the demand element. Elements required to model the water distribution are part of the second category and consist of nodes that allow aggregating or distributing the supplies and demands. The third category comprises elements that impose constrains to the water distribution such as pressure valves and booster stations. Pressure valves and booster stations are characterized by a specific maximum capacity and elevation as well. The model consists of a library of objects, one object for each system component necessary to implement a specific water distribution system.

The steps to build the system are as follows: 
1. Individualizing the elements from the three categories needed to represent the specific master plan,

2. Instantiating the elements (e.g., assigning input parameters to each element such as for instance max capacity) based on the data reported by the master plan, and

3. Connecting these elements together forming the water distribution network.

The hydraulic network is internally represented as a system of integro-differential equations in order to calculate the time evolution of the system.

Once the model of a specific city is developed, it can be converted in a stand-alone application and the user can explore the consequences of different disruption scenarios. 


\section{EPANET}

\section{PURPOSE}

EPANET is a hydraulic and water quality modeling software for pipe network. The tool was developed by EPA to support utilities operators in long term water network planning but can be also used for consequences assessment. Based on water utility network and set of operations, EPANET can simulate the effects on a water distribution system of multiple assets disruption in terms of changes in pressure in the system. Geographical areas with low pressure are recognized as areas where demand is not met.

Unlike most of the tools previously analyzed, simulating a distribution system using EPANET requires experts in hydraulic simulations and modeling and a large amount of data, which describes the physical infrastructures.

\section{APPROACH}

EPANET is a network model that simulates hydraulic behavior of a water distribution system. It models all the components of the physical infrastructure including pipes, pumps, tanks, and reservoirs. Figure 4 shows as an example the EPANET network model for Santa Fe, NM. Each network nodes/junctions represents a service connection with associated an aggregated water demand. Consequences of system disruptions such the loss of an asset (e.g., tank, pipe, and pump) is represented in EPANET as a inadequate pressure in the system that can lower flow rates leading to a failure in delivering potable water. EPANET tool can simulate the dynamics in time of the failure and localizing nodes with low pressure. 


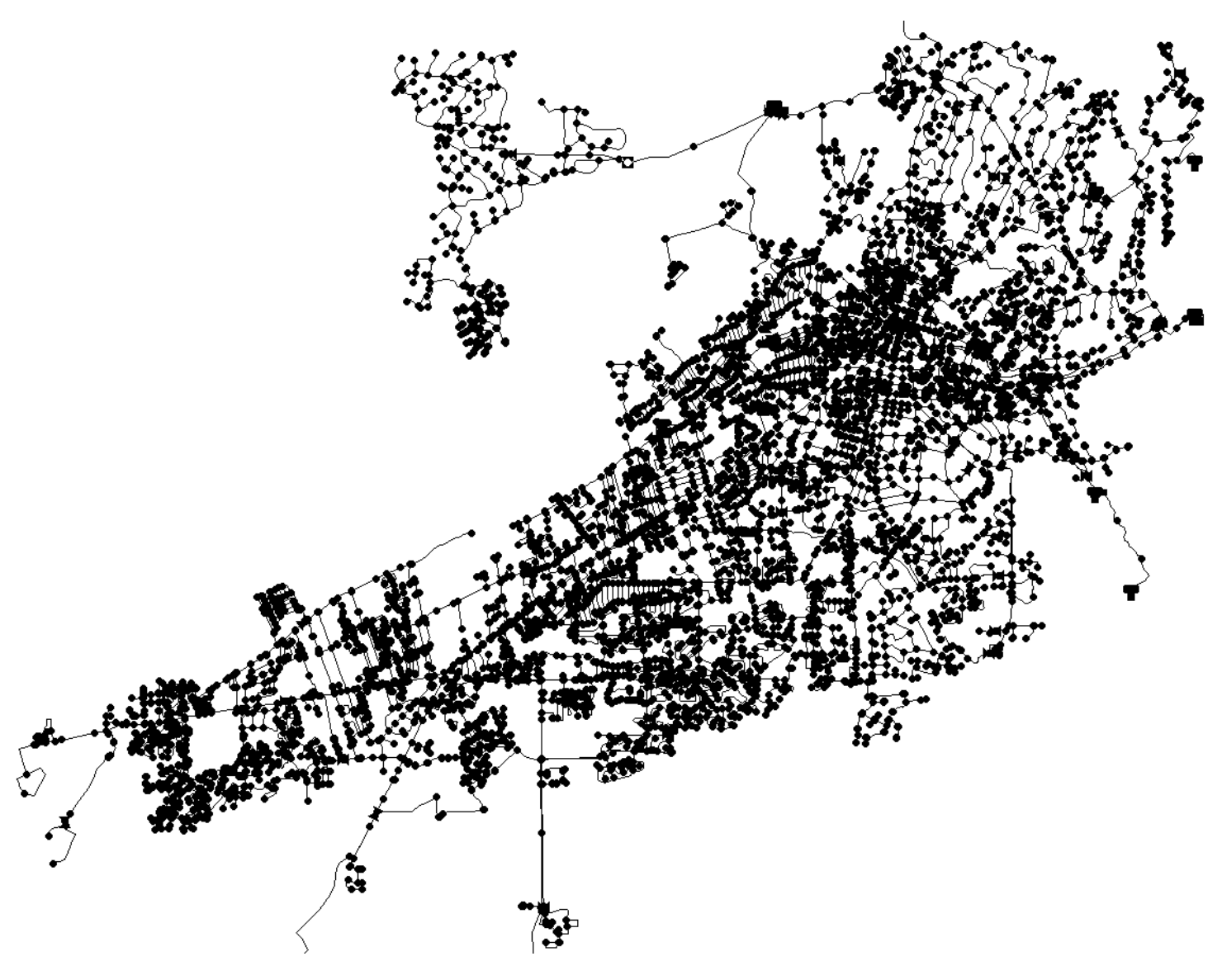

Figure 4 EPANET model for Santa Fe, NM.

The EPANET network modeling approach in assessing consequences results to be more accurate and more rigorous than qualitative assessments tools such as for example WHEAT and VSAT. However, assessing consequences using EPANET presents two challenges. Running EPANET requires a large amount of data necessary to describe the water distribution system and the system operations. The challenge is that not all water utilities have the data of all-pipes model and in case these data exists utilities do not share it. The second challenge is intrinsic into the approach used to model the hydraulic behavior of the system. EPANET is a demand-driven model meaning that the demand is always met even when the pressure in the system decreases. For this reason, EPANET can be used to identify geographical areas with loss of service, but cannot quantify the amount of unmet demand. Algorithms have been developed to covert demand-driven simulations to pressure-driven simulations in order to correctly estimate unmet demand ${ }^{10}$.

${ }^{10}$ J.M. Wagner, U. Shamir, D.H. Marks "Water distribution reliability: Simulation methods." (1988) Journal of Water Resources Planning and Management, 114(3), 276-293 
The EPANET Pressure Dependent Demand (EPANET-PDD) is a modification of EPANET to a pressure-driven model as described in the following section.

EPANET is available for download free of charge at http://www2.epa.gov/waterresearch/epanet. 


\section{EPANET PRESSURE-DEPENDENT DEMAND (EPANET-PDD)}

\section{PURPOSE}

Developed by Los Alamos National Laboratory as a support of DHS goals, the EPANET Pressure Dependent Demand (EPANET-PDD) is a simulation tool that estimates the consequences of drinking water distribution system disruptions. EPANET-PDD is a modification of the open-source EPANET model. This modification more accurately represents system water delivery shortage in the event of asset disruption. In addition, the simulation tool estimates impacts on the population in terms of number of people without drinking water and their geospatial location if an asset fails. The model also calculates impacts on economic activities. As with the EPANET model, EPANET-PDD is not tool for self-assessments of consequences. The EPANET-PDD simulation tool uses the allpipe network model from the water utility.

\section{APPROACH}

EPANET and other hydraulic models that evaluate system performance under adverse conditions (e.g., contingencies) often have simulations indicate negative pressures. Negative pressures are an artifact of the network solver and do not actually exist in a water distribution systems. Rather, negative to low pressures should be interpreted as showing locations where the specified demand cannot be met. ${ }^{11}$ Negative pressures arise because the formulations of the equation enforce demand satisfaction at the expense of energy. That is, demand at a junction is always constant and does not reduce drops in system pressure. In reality, water demand is a function of system pressure. When pressure drops below a reasonable threshold, the ability to supply water drops and, therefore, demand should be modified.

EPANET does not account for the pressure-demand relationship and therefore oes not allow accurately localizing unmet demand in a water distribution system. With EPANETPDD tool LANL implemented a pressure-dependent approach in the EPANET software in order to simulate accurately unmet demand in a urban water distribution system. The approach developed is based on Rossman ${ }^{12}$ work. EPANET-PDD allows identifying areas of shortages in the system. EPANET-PDD also calculates the people without drinking water service and their locations. In the water distribution network, each junction with demand corresponds to a service area. The service area is a geospatial representation of an area that receives water from the junction. Each service area has an estimate of the population with the geographical unit, in addition to economic activity and other critical infrastructure. As with WHEAT, the economic activity calculation is based on the Input Output approach and on economic data from the U.S. Census at tract levels. This

\footnotetext{
${ }^{11}$ Walski, Thomas M., Donald V. Chase, Dragan A. Savic, Walter M. Grayman, Stephen Beckwith, and Edmundo Koelle. Advanced water distribution modeling and management. Haestad Press, 2003.

${ }^{12}$ Ang, Wah Khim, and Paul W. Jowitt. "Solution for water distribution systems under pressure-deficient conditions." Journal of water resources planning and management 132, no. 3 (2006): 175-182.
} 
approach calculates direct and indirect regional impacts in terms of jobs and gross domestic product loss.

EPANET-PDD tool is a DHS tool. A technical report is available from the Energy and Infrastructure Analysis Group at Los Alamos National Laboratory upon request. 


\section{CONCLUSION}

The approach to consequence estimation is an important difference among the considered tools. These tools may be divided in two categories: (1) tools that provide water utilities with a learning framework to aid in self-assessments of consequences; and (2) tools that identify critical assets and quantify consequences under specific event scenarios using a system modeling approach. While the tools in the first category are valuable guides for self-assessment of systems and facilities, they do not provide a way to calculate consequences. Consequences and localitation of critical system assets are the main inputs of the tools and are quantified by the utilities. As a consequence, the results of the risk and vulnerability assessments of these tools are highly dependent on the ability of the utility to identify critical assets and estimate consequences. This first category includes VSAT, WHEAT, CREAT, ANL-RI, RAMP-W, and SEMS models.

TEVA-SPOT, CIP-DSS, WSMP, EPANET, and EPANET-PDD are part of the second category. These models simulate the consequences of a system disruption modeling the system components. These models require some utility-level knowledge of the water distribution system network: detailed of all pipe distribution system network (e.g., EPANET, TEVA-SPOT) or a simplified sketch of the network (WSMP), including major junctions and assets, or system-level information about the major components of the water system, such as reservoir capacities and average water demand (CIP-DSS). The main purpose of these tools is to identify critical assets and quantify the consequences of disruption. Assessing the associated risks and system vulnerability based on the estimated consequences is secondary. 